\title{
Herding Behavior in Emerging and Frontier Stock Markets During Pandemic Influenza Panics
}

\author{
Quang Thu LUU', Hien Thi Thu LUONG ${ }^{2}$
}

Received: July 03, 2020 Revised: July 19, 2020 Accepted: August 10, 2020

\begin{abstract}
We apply Return Dispersion Model by calculating CSAD (Cross-sectional standard deviation of return) and State Space Model to identify herding behavior in the period of pandemic (H1N1 and COVID-19). Employing data from TEJ and Data Stream, this paper examines whether the herding behavior is existing in Vietnam and Taiwan stock market, especially during pandemic influenza. We compare the differences in herding behavior between frontier and emerging markets by examining different industries across Vietnam and Taiwan stock market approaches. The results indicate solid evidence for investor herd configuration in the various industries of Vietnam and Taiwan. The herding impact in the industries will be greater than with the aggregate market. The different industries respond differently to influenza pandemic panics through uptrend and downtrend demonstrations. Up to 12 industries were found to have herding in Vietnam, while Taiwan had only 5 of 17 industries classified. Taiwan market, an emerging and herding-level market, has changed due to the impact of changing conditions such as epidemics, but not as strongly as in Vietnam. From there, we see that the disease is a factor that, not only creates anxiety from a health perspective, but also causes psychological instability for investors when investing in the market.
\end{abstract}

Keywords: COVID-19,Herding Behavior, Emerging Markets

JEL Classification Code: E44, F31, F37, G15

\section{Introduction}

The crowd effect, also known as 'herding behavior' is a common psychological phenomenon in the socioeconomic life, including in the behavior of investors in the financial market. There are several explanations for the behavior of a herd. Institutional investors, for example, may harbor remuneration, and investors may receive data from former investors' actions or respond to the appearance of fundamental information. However, this behavior is a factor that could lead to financial crisis contagion in case panic situations

${ }^{1}$ First Author.Banking University of Ho Chi Minh City, Vietnam[Postal Address: 56 Hoang Dieu 2, Linh Chieu, Thu Duc, Ho Chi Minh City, 700000, Vietnam] Email: quanglt@buh.edu.vn

${ }^{2}$ Corresponding Author. Banking University of Ho Chi Minh City, Vietnam[Postal Address: 56 Hoang Dieu 2, Linh Chieu, Thu Duc, Ho Chi Minh City, 700000, Vietnam] Email: hienluong521999@gmail.com

(c) Copyright: The Author(s)

This is an Open Access article distributed under the terms of the Creative Commons Attribution Non-Commercial License (https://creativecommons.org/licenses/by-nc/4.0/) which permits unrestricted non-commercial use, distribution, and reproduction in any medium, provided the original work is properly cited.
Since the outset, financial contagion was related to the emerging market, that is, in the less advanced, mostly former imperial world, the main sources of 'infection'. Such geographical environments were the very areas of the war against virulent 'emerging diseases' and especially the Southeastern Asian countries and Latin America. In 1997, 18 hospitalize people and six of them dead underlined the relationship between these two types of 'emergence' as a result of the term 'Asian flu' used in the description of the 1997 financial crisis and the outbreak of H5N1 avian flu in Hong Kong. From the beginning of the 21 st century up to now, humans have faced more influenza panic such as SARS (2004), MERS (2012), H1N1 (2009) coincided with a severe global financial downturn (2007-2008), and recently COVID-19 pandemic caused such global incertitude that stock markets have fallen most dramatically since COVID-19 was recognized as a pandemic by the World Health Organization on 30 January 2020

As a result, there have been two progressively-related conceptions of the biological and economic risk. In addition, the so-called 'emerging markets' have in addition contributed to public health and financial crises in sociopolitical frameworks.Vietnam stock market is classified 
as 'frontier market' by MSCI because of lack of criteria including efficiency trading and now trying to be leveled up into emerging market in near future. So, Vietnam stock market affected by pandemic influenza panic is inevitable. In addition, when considering the specific characteristics of the stock market in Vietnam, it is still in the development and selfimprovement stage with many difficulties and challenges. At the same time, for investors with small and medium capital, the reception of official news sources becomes difficult. Since then, the application of valuation models as well as many erroneous and inaccurate investment strategies cause great losses to investors in the market, leading to investors becoming highly dependent on 'crowds' or 'big men' have a large number of transactions on the market, a phenomenon of 'price manipulation' that is common in Vietnam's stock market. That is one reason that the market is not really effective, greatly affecting the market upgrade.

The new contribution of this paper is identifying the difference between the herding behavior of emerging market and frontier market during pandemic, especially the ongoing COVID-19 epidemic. The author compares herding behavior of investors in Vietnam with Taiwan stock market in an attempt to compare emerging and frontier markets in the occurrence of influenza pandemic, which factor may lead to economics crisis to get the most objective comments and draw the salient features of two markets. Since then, this research will become the basis for investors to rely on to make decisions and manage their portfolios effectively as well as policymakers to can give suitable directions to manage the stock market.

\section{Literature Review}

\subsection{Herding Behavior}

The herding of financial markets demonstrates the mechanism by which market players trade in the same way at the same time and by converging to the consensus their behavior. There are various explanations for the actions of herding behavior. Analysts may work out the credibility of protecting the profits of institutional investors, and investors may infer information from prior investors' behavior or respond to fundamental data. The discrepancies between Bikhchandani and Sharma (2000) are between investors who are faithfully copying the actions of others with similar simple ('spurious' herding) knowledge and investors who intentionally copy ('intentional' herding). Previous studies are performed by using market-aggregated data as well as examining the herding of consumer opinion (i.e., Chang, Cheng, \& Khorana, 2000), with an analytical paper focusing on institutional investor herding (i.e., Kallinterakis, 2007).

Over the past several decades, both researchers and experts have been paying much attention to herding behavior. A large number of scientific and experimental studies have been conducted to explore the development and effects on financial markets of this syndrome. The presence of herders can influence asset-pricing models, as they have an effect on actions on stock price changes and have commensurately an effect on stock return and risk (Olsen, 1996). Traders and investors following trends can exacerbate the instability of returns and, thus, the financial systems can be invaded and destroyed, throughout a crisis era. Further analysis indicates that the herd psychology creates market chaos and generates opportunities for investors (Jalal et al, 2020)

Chiang and Zheng (2010) are carrying out a survey on 18 advanced and developing economies in a comprehensive herding study. As investors in Asian economics, both up and down markets have a level of herding. The authors do not find any evidence of herding in the US and Latin American markets. The conclusive proof that this behavior is present in the analysts' forecast is confirmed by studies carried out by Olsen (1996). In mutual funds, Wermers (1999) also detected signs of herding. Chen et al. (2012) argue that the scale of the company forms the primary variable in taking decisions in the Taiwanese stock market by international fund managers. Furthermore, Lin and Swanson (2003) note that the shortterm performance of foreigners on large stocks is, after checks on company sizes, better than results on small stocks since the percentage of the positive net shares purchased on large stocks is greater than the quantity on the Taiwan stock exchange (TSE) in small stocks. This can also occur on the stock market in Vietnam. Few Vietnamese stock exchange research, especially with regard to herding problems, has been carried out. The study by Kallinterakis (2007) has included an exception from this analysis. It examined the herding based on the component responsiveness in assets at a cross-cutting stage of the market (cross-cutting dispersion of all the betas on the markets. On the conceptual side, several past documents analyze the existence, summarized in Vo and Phan (2017), of herds in both advanced and developing stock markets. All of this focuses on analyzing the conduct of herds under various circumstances on the market and the effect on this phenomenon of the global financial crisis.

\subsection{Historical Global Pandemic Influenza Review}

Influenza (mostly known as 'flu') is a contagious viral illness mainly triggered by the influenza virus $\mathrm{A}$ or $\mathrm{B}$ according to WHO's meaning. It primarily affects the top respiratory bodies (i.e., the nose, throat, bronchi and seldom the lungs), but it could include other bodies such as the heart, brain, and muscles. This happens globally, causing serious pandemic, epidemic or seasonal illness and death.

In 2003, the SARS was the epidemic that affected the rich urban communities most severely. In complex hospital environments, SARS spreads most productively. One theory had vanished. 
The $2009 \mathrm{H} 1 \mathrm{~N} 1$, the first of the 21st century, influenza pandemic showed the rapid spreading of a new virus around the world. It revealed how anything on the other side of the world can be the case that eventually bursts with all eyes centered on H5N1 in Asia. Yet, a lucky one was the biggest outcome from the H1N1 virus: the pandemic was much milder than many predicted.

And now the world is confronted by novel coronavirus. As of this writing, there have been approximately 570,000 confirmed cases of the new disease, called COVID-19, resulting in more than 26,000 deaths worldwide (reported by WHO). There are travel restrictions due to the coronavirus in more than 100 countries. Its growth left corporations worldwide with cost counts.

The COVID-19 epidemic has only recently been identified by humans, hence there are few studies on COVID-19 affecting financial markets. For example, Alam, Alam, and Chavali (2020) indicate that Indian stock market has positive relationship with average abnormal returns during the lockdown time by COVID-19. Another broader study (Khan et al., 2020) is conducted on the stock markets of sixteen countries, reveals that investor psychology is not affected by information about COVID-19 at the beginning of the pandemic. However, once WHO confirmed the humanto-human transmissibility of COVID-19, all stock markets reacted negatively. This paper's contribution is the first study about the herd behavior of investor in the context of the COVID-19 pandemic.

\section{Research Methodology}

\subsection{Data}

Based on five parameters of market (ownership, capital flows, operating mechanism performance, availability of investment tools, and institutional mechanism stability), Morgan Stanley Capital International (MSCI) classify Vietnam as frontier market and Taiwan as emerging market. Hence, in the paper, the authors take Vietnam as proxy of the frontier market and Taiwan as the proxy of the emerging market. In detail, daily trading data for all stocks (about 389 stocks) on the Ho Chi Minh Stock Exchange (HSX) and the VN-Index is collected. This data is large enough to be representative for Vietnam stock market, as well as all stocks listed on Taiwan Stock Exchange (about 1074 stocks) and TWSE - daily index to represent Taiwan stock market in the range of 20 years from 2000 to the present. Data were extracted from data stream and divided into groups corresponding to different industries to conduct analysis from an industry perspective according to global industry classification standard GICS. In addition, we also assess the period of influenza panics happening in history as well as currently affecting the behavior of investors. Specifically, the data will be divided into 6-month periods before and after pandemic appear to test herding behavior in the short term. The time points selected for this paper is H1N1 pandemic (May 2009) and COVID-19 pandemic (December 2019).

\subsection{Methodology}

This article implements two frameworks of market herding measurement: Return Dispersion Model by calculating CSAD (Cross-sectional standard deviation of return) variable, proposed by Christie and Huang (1995) and Chang (2000), and State Space Model first proposed by Hwang and Salmon (2004). This analysis defines if herding behavior is present and how it impacts on stocks. The results of herd forming among investors in Taiwan and Vietnam have been compared and been contrasted with a broad range of data.

\subsubsection{Return Dispersion Model}

According to Muth's (1961), the assumption between profit distribution and the average market has a positive relationship. An empirical approach based on the quadratic relationship between CSAD and market returns is proposed as a linear regression model (Chang et al., 2000; Henker et al., 2006):

$$
C S A D=\alpha+\gamma_{1}\left|R_{m, t}\right|+\gamma_{2}\left(R_{m, t}\right)^{2}+\varepsilon_{t}
$$

The CSAD coefficient can be considered as representing the crowd phenomenon when it is shown that the correlation relationship between the profit distribution of portfolio assets and market returns. When investors become dependent and trade according to the general trend of the market, the dispersion will decrease gradually and towards the market average, leading to a non-linear relationship and achieving a negative value between CSAD and market returns as $\left(R_{m, t}\right)^{2}$. When the market becomes tense and the crowds occur, then the coefficient $\gamma_{2}$ s negative (Economou et al., 2011). CSAD reaches its maximum value when $R_{m, t}^{*}=-\gamma_{1} / 2 \gamma_{2}$, This indicates that $\gamma_{2}$ has a negative value when and only when there is a crowd act on the market.

According to Chang et al. (2000), crowd behavior occurs when extremes occurs. From there, the author developed the regression model apply in particularly for influenza panic. Moreover, the author assessed the phenomenon of herding from the perspective of different industries. Therefore, the regression model applied for each specific industry is changed as follows, where $C_{S A} D_{P}^{\text {Panic }}$ is the cross-sectional absolute deviation of weighted average of return of the industry under consideration:

$$
C S A D_{P}^{\text {Panic }}=\alpha+\gamma_{1}^{\text {Panic }}\left|R_{m, t}\right|^{\text {Panic }}+\gamma_{2}^{\text {Panic }}\left(R_{m, t}^{\text {Panic }}\right)^{2}+\varepsilon_{t}
$$




\subsubsection{State Space Model}

The next model to study herding behavior, which was initially suggested by Hwang and Salmon (2004), is the State Space Model. Concentration is more on the cross-sectional variability of factor sensitivities than on the return on herding estimation. Instead, Hwang and Salmon have made a measure of herding behavior, using a single market return model that uses the relative dispersion of the variance of all market assets. State Space Model is then formed as:

$$
\begin{aligned}
& \log \left[\operatorname{Std}_{c}\left(\beta_{i m t}^{b}\right)\right]=\mu_{m}+H_{m t}+\vartheta_{m t} \\
& H_{m t}=\phi_{m} H_{m t-1}+n_{m t}
\end{aligned}
$$

Where: $h_{m \mathrm{t}}$ is a latent herding parameter that changes over time, $h_{m t} \leq 1$, and conditional on market fundamentals; $\beta_{i m t}^{b}$ is the market's biased short run conditional expectation on its beta at time t; $\operatorname{Std}_{c}\left(\beta_{i m t}^{b}\right)$ is the standard deviation of $\beta_{i m t}^{b} ; \log \left[\operatorname{Std}_{c}\left(\beta_{i m t}^{b}\right)\right]=\mu_{m}+\vartheta_{m t}$ in which $\mu_{m}=E\left[\log \left[\operatorname{Std}_{c}\left(\beta_{i m t}^{b}\right)\right]\right]$ and $\vartheta_{m t} \sim \operatorname{iid}\left(0, \sigma_{m v}^{2}\right)$; and finally $H_{m t}=\log \left(1-h_{m t}\right)$ and $n_{m t} \sim i i d\left(0, \sigma_{m n}^{2}\right)$.

These equations with Kalman filter estimation are the regular state space model. The subject of the model in the latent state variable, $H_{m t}$, the state equation, is essentially the dynamism of movement patterns. If $\sigma_{m n}^{2}=0$, there is no evidence of the herding comportment, which means that $H_{m t}=0$ for all t. $H_{m t}$ will evolve over time with this model, a dynamic herding mechanism. If the value of $\sigma_{m n}^{2}$ is significant, then it means that it has a herd and significant $\phi$ implies the validity of this autoregressive structure. Moreover, the author assessed the phenomenon of herding from the perspective of different industries. Therefore, the State space model applied for each specific industry is changed as follows where $p$ is portfolio of stocks of industries.

$$
\begin{aligned}
& \log \left[\operatorname{Std}_{c}\left(\beta_{i p t}^{b}\right)\right]=\mu_{p}+H_{p t}+\vartheta_{p t} \\
& H_{p t}=\phi_{p} H_{p t-1}+n_{p t}
\end{aligned}
$$

Where: $H_{p t}=\log \left(1-h_{p t}\right)$ and $n_{p t} \sim i i d\left(0, \sigma_{p n}^{2}\right)$

\section{Empirical Results}

In this part, the author makes remarks on the results of testing herding behavior by both models: Return dispersion model and State space model at different levels including market level, industries level and especially in the period market stress by implication of influenza pandemic panics (first is H1N1 and recently is COVID-19).

\subsection{Return Dispersion Model Results}

\subsubsection{Herding Behavior Testing in Perspective of Whole Market of Vietnam and Taiwan}

Patterson's and Sharma's (2007) study finds the use of day-to-day data to be best suited to measuring business herding behavior. Both markets, regardless of their emerging or frontier environment, were extensively herded according to model test results. Although Taiwan's equity market in comparison to the market in Vietnam is comparatively matured and categorized as an emerging market, its herding behavior was still strong. From Table 1, for the Vietnamese market, the coefficient of daily data $R_{m, t}^{2}$ can be found to be negative, the coefficient of $\left|R_{m, t}\right|$ is positive and significant at $1 \%$ shows that the Vietnamese stock market has herding behavior. Similarly, Taiwan market was also noticed the phenomenon of herding in the market with $\gamma_{2}<0, \gamma_{1}>0$ and significant at $1 \%$.

Earlier studies have shown that in Asian capital markets, herding behavior is commonly present (Chang et al., 2000; Chiang \& Zheng, 2010). Therefore, after expanding the sample size and monitoring for market return parameters, it is important to check whether the industry herding is still relevant. However, the results indicate that, even though absolute return and returns square are used as control variables on the stock market, the herding behavior influences on industries still exists, but not so dramatically, though market splits between industries and experiments are carried out using the return dispersion model.

Table 1: Regression results for $C S A D=\alpha+\tilde{a}_{1}\left|R_{m, t}\right|+\tilde{a}_{2}\left(R_{m, t}\right)^{2}$ of Vietnam and Taiwan stock markets

\begin{tabular}{|l|c|c|}
\hline \multirow{2}{*}{ Variables } & \multicolumn{2}{|c|}{ CSAD } \\
\cline { 2 - 3 } & Vietnam & Taiwan \\
\hline$\gamma_{1}$ & $1.84^{* * *}$ & $1.60^{* * *}$ \\
\hline & $(0.06)$ & $(0.03)$ \\
\hline$\gamma_{2}$ & $-28.46^{* * *}$ & $-31.19^{* * *}$ \\
\hline$\alpha$ & $(1.95)$ & $(1.09)$ \\
\hline & $0.007^{* * *}$ & $0.007^{* * *}$ \\
\hline Observations & $(0.00)$ & $(0.00)$ \\
\hline R-squared & 4,065 & 4,090 \\
\hline
\end{tabular}

Note: ${ }^{* * *},{ }^{* *}$ and ${ }^{*}$ indicates significant at $1 \%, 5 \%$ and $10 \%$ level of significance based on t-statistics.

If $\gamma_{1}>0$ and $\gamma_{2}<0$ and is significant, there is herding behavior existence. 


\subsubsection{Herding Behavior Testing in Perspective of Different Industries of Vietnam and Taiwan}

We noticed from the Table 2 that herding appears only in Insurance and Materials in Vietnam and Real Estate in Taiwan when $\gamma_{1}$ positive, $\gamma_{2}$ is negative reaches a statistical value of $1 \%$. For the remaining industries, there is a lack of judgment, except that Utilities in the Vietnamese market does not recognize the phenomenon of herding with $\gamma_{2}$ reaching positive values with significance level of $1 \%$. As approaching by industry-level, the CSAD model does not show the effectiveness when it is impossible to find clear evidence of herding behavior as tested with market size indicated earlier.

\subsubsection{Herding Behaviors of Different Industries during Influenza Pandemics}

Vo and Phan (2017) stated that Vietnam stock market has herds even under different market conditions. We now turn to the effect of the outbreak of the global influenza pandemics in 21st century (H1N1 May 2009 and COVID-19 December 2019) over herding in our sample markets' different industries level to compare with Taiwan. However, the result shows by this approach is still not strong. When considering the influenza pandemic factor, the author aims at the pandemic H1N1 when it was declared a pandemic in May 2019 by WHO.

According to Table 3, for the Vietnam market in the period before the occurrence of the disease, only the Food beverage had significance level lower than 5\%. However, during the period of occurrence to the end of the epidemic, the herding phenomenon was no longer noticed in the Food beverage industry, but was noticed in the Transportation industry where herding appeared. The same can be seen in the Taiwan market for the Energy industry, where herds in the market after a pandemic appears, but before that time, the rest of the industry did not notice the crowd phenomenon.

For the period before and during the COVID 19 pandemic, the Vietnamese stock market lacked evidence for confirming the herding phenomenon when all cashew industries were not statistically significant. On the other hand, for Taiwan market, since COVID 19 pandemic occurred, Food beverage had herding phenomenon, but before that, only the Healthcare industry had it. Together with the result from the $\mathrm{H} 1 \mathrm{~N} 1$ pandemic, it is conceivable that the epidemic is a factor that causes a change in investor behavior as well as crowds in the markets (see Table 4).

Table 2: Regression results for $C S A D=\alpha+\tilde{a}_{1}\left|R_{m, t}\right|+\tilde{a}_{2}\left(R_{m, t}\right)^{2}$ in different industries

\begin{tabular}{|c|c|c|c|c|c|c|}
\hline & & Vietnam & & & Taiwan & \\
\hline & $\gamma_{1}$ & $\gamma_{2}$ & $\alpha$ & $|r|$ & $\rho_{2}$ & $\alpha$ \\
\hline Automobiles & $0.006^{* *}$ & 0.011 & $0.0002^{* * *}$ & $0.0020^{* *}$ & -0.016 & $0.00007^{* * *}$ \\
\hline Bank & -0.043 & $7.351^{* * *}$ & $0.002^{* * *}$ & $0.0125^{\star * *}$ & -0.019 & $0.0003^{* * *}$ \\
\hline Capital goods & $0.043^{* *}$ & -0.559 & $0.004^{* * *}$ & 0.0013 & -0.012 & $0.0001^{* * *}$ \\
\hline Commercial & -0.000 & 0.000 & $0.00004^{* * *}$ & -0.0010 & 0.006 & $0.00005^{* * *}$ \\
\hline Consumer durables & -0.000 & $0.221^{* * *}$ & $0.0005^{\star * *}$ & $0.0058^{*}$ & -0.068 & $0.0007^{* * *}$ \\
\hline Consumer services & 0.000 & -0.010 & $0.00005^{* * *}$ & -0.0010 & 0.006 & $0.00005^{* * *}$ \\
\hline Diversified Financials & $0.052^{* \star \star}$ & -0.430 & $0.0012^{\star * \star}$ & 0.0010 & 0.042 & $0.0001^{* * *}$ \\
\hline Energy & -0.006 & $0.572^{\star \star *}$ & $0.0008^{* * *}$ & 0.0010 & -0.002 & $0.00003^{* * *}$ \\
\hline Food beverage & $0.047^{* * *}$ & -0.165 & $0.002^{* * *}$ & 0.0002 & -0.007 & $0.00001^{* * *}$ \\
\hline Health care & 0.000 & 0.029 & $0.0002^{* * *}$ & 0.0006 & -0.015 & $0.00006^{* * *}$ \\
\hline Insurance & $0.028^{* * *}$ & $-0.453^{* *}$ & $0.0003^{* * *}$ & $0.0096^{* * *}$ & 0.011 & $0.0003^{* * *}$ \\
\hline Materials & $0.050^{* * *}$ & $-0.587^{*}$ & $0.0027^{\star \star \star}$ & 0.0028 & 0.081 & $0.0003^{* * *}$ \\
\hline Pharmaceuticals & -0.003 & $0.167^{* * *}$ & $0.0001^{* * *}$ & $-0.0033^{* *}$ & 0.067 & $0.0002^{* * *}$ \\
\hline Real estate & $0.064^{* *}$ & -0.539 & $0.0036^{\star * *}$ & $0.0050^{* * *}$ & $-0.069^{* *}$ & $0.0001^{* * *}$ \\
\hline Transportation & $0.027^{* * *}$ & -0.075 & $0.0008^{* * *}$ & $0.0060^{*}$ & -0.060 & $0.0004^{* * *}$ \\
\hline Technology & $0.007^{\star \star *}$ & 0.024 & $0.0003^{\star * *}$ & -0.0011 & 0.021 & $0.0001^{* * *}$ \\
\hline Utilities & $0.014^{* * *}$ & $0.373^{* *}$ & $0.0006^{* * *}$ & $0.0003^{*}$ & -0.005 & $0.00001^{* * *}$ \\
\hline
\end{tabular}

Note: ${ }^{* * *},{ }^{* *}$ and ${ }^{*}$ indicates significant at $1 \%, 5 \%$ and $10 \%$ level of significance based on t-statistics.

If $\mathrm{Y}_{1}>0$ and $\mathrm{Y}_{2}<0$ and is statistical significance, there is herding behavior existence. 
Table 3: Regression coefficient results during H1N1 pandemic

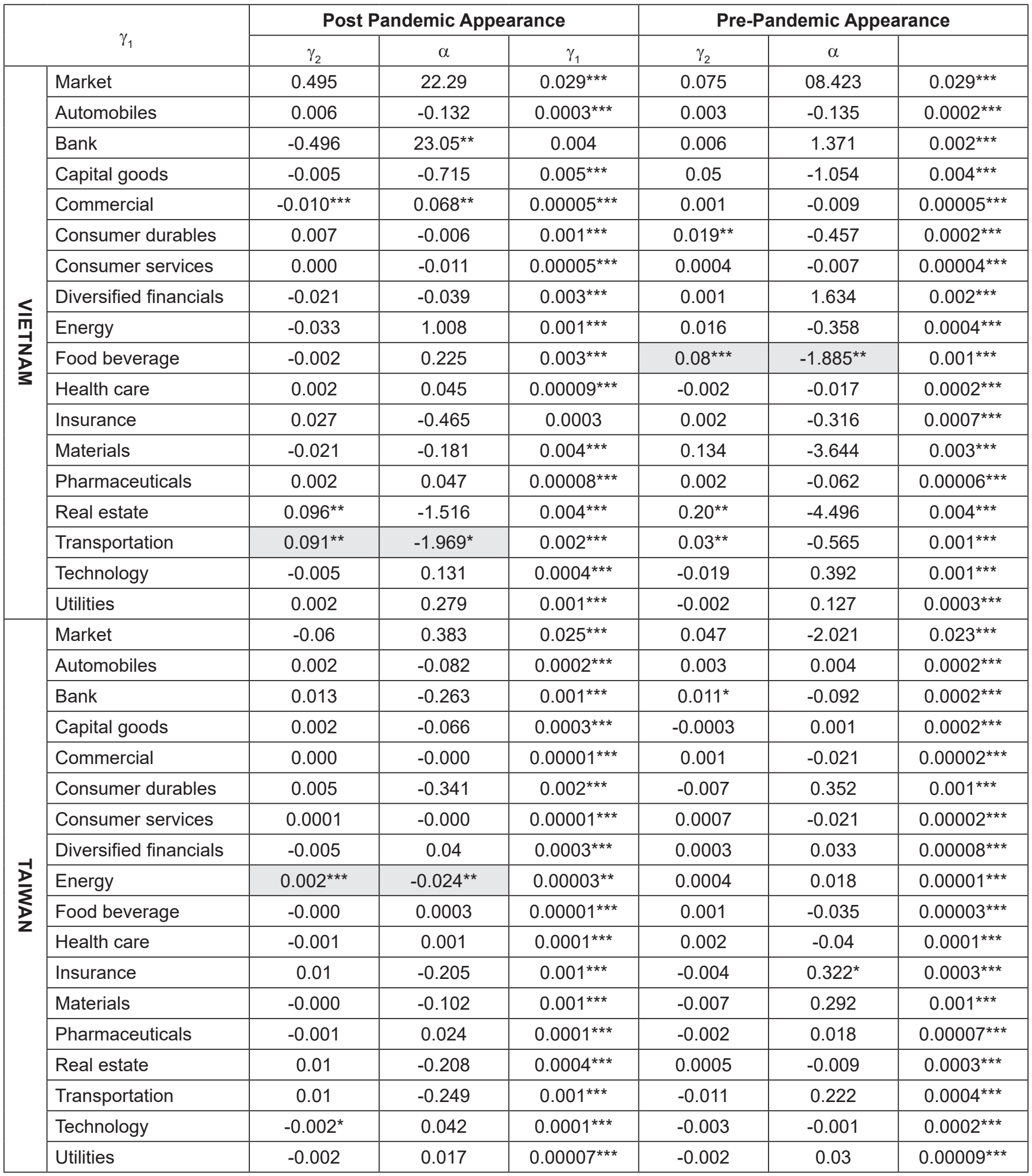


Table 4: Regression results during COVID-19 pandemic

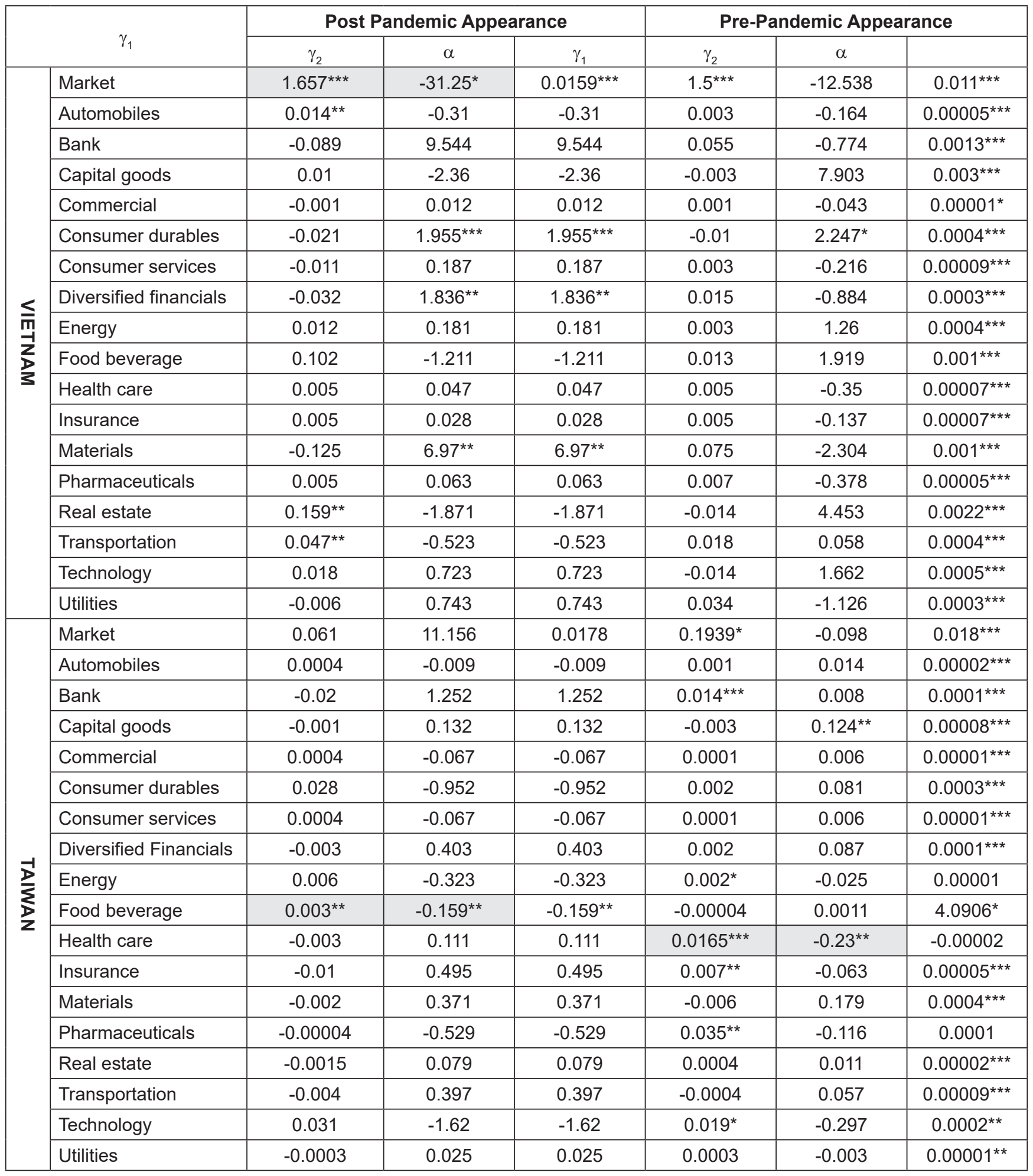

Note: ${ }^{* * *},{ }^{* *}$ and * indicates significant at $1 \%, 5 \%$ and $10 \%$ level of significance based on t-statistics.

If $\gamma_{1}>0$ and $\gamma_{2}<0$ and is statistical significance, there is herding behavior existence. 
However, even though the time limit for observation was shorter, the model using CSAD index did not produce clear results by looking at the long term. This shows that the weakness of this model in applying market analysis in different conditions only occurs in the short term. This model only shows the phenomenon of herding appearing in the sectors that are particularly affected or particularly positive due to diseases such as Food Beverage, Transportations, Healthcare and Energy. In addition, signs of other industries are not found in this model.

\subsection{State Space Model}

\subsubsection{Herding Behavior Testing in Perspective of Different Industries of Vietnam and Taiwan}

In order to increase the accuracy of herding detection results for the two target markets, the author conducted the State space model with evidence of herding through $\phi_{\mathrm{m}}$ showing persistence of herding and $\sigma_{m \eta}^{2}$ that are significant. For Vietnam market, herding industries include Capital Goods, Commercial, Consumer Services, Diversified Financials, Energy, Food Beverage, Insurance, Materials, Pharmaceuticals, Real-Estate, Transportation and Technology with $\phi_{\mathrm{m}}$ and $\sigma_{m \eta}^{2}$ that are significant. In which, Transportation is considered to be the most obvious phenomenon of herding with the highest value of $\phi_{\mathrm{m}}$ and Materials is the lowest value of $\phi_{\mathrm{m}}$.

On the other hand, for Taiwan market, according to Table 5, Capital Goods, Commercial, Consumer Services, Diversified Financials and Real Estate have herding phenomenon with the statistical significance of 5\%. At the same time, herding's persistence on industries in Taiwan market was found to be lower than Vietnam market.

\subsubsection{Implications of Influenza Pandemic on Herding Level among Industries}

The results in the previous section show the presence of herding in both Vietnam and Taiwan at the industry level through the statistical significance of the coefficients estimated from the State space model. In this section, graphs

Table 5: State space model coefficient results

\begin{tabular}{|c|c|c|c|c|c|c|c|c|}
\hline & \multicolumn{4}{|c|}{ Vietnam } & \multicolumn{4}{|c|}{ Taiwan } \\
\hline & $\mu_{\mathrm{m}}$ & $\varphi_{\mathrm{m}}$ & $\sigma_{\mathrm{mv}}^{2}$ & $\sigma_{\mathrm{m}}^{2}$ & $\mu_{\mathrm{m}}$ & $\varphi_{\mathrm{m}}$ & $\sigma_{\mathrm{mv}}^{2}$ & $\sigma_{\mathrm{m}}^{2}$ \\
\hline Market & $-0.2577^{* * *}$ & $0.8625^{\star * *}$ & $0.0517^{* * *}$ & $0.0267^{* * *}$ & $0.9512^{* * *}$ & -0.0163 & 2.3151 & 7.341 \\
\hline Automobiles & $-0.905^{\star \star *}$ & $0.9818^{* * *}$ & $0.3428^{* * *}$ & 0.0077 & $-1.0891^{* * *}$ & $0.7576^{* \star *}$ & $0.1979^{* * *}$ & 0.027095 \\
\hline Bank & $-1.168^{* * *}$ & $0.9336^{* * *}$ & $0.4352^{* * *}$ & 0.0206 & $-1.0602^{* * *}$ & $0.9833^{* * *}$ & $0.0647^{* * *}$ & 0.001245 \\
\hline Capital Goods & $0.0109^{*}$ & $0.9105^{* * *}$ & $0.4181^{* * *}$ & $0.0283^{* *}$ & $-0.6909^{* * *}$ & $0.1506^{* *}$ & 0.000000 & $0.0846^{* * *}$ \\
\hline Commercial & $-0.652^{* * *}$ & $0.7789^{* * *}$ & $0.4131^{* * *}$ & $0.0877^{*}$ & $0.4866^{\star \star *}$ & $0.6845^{\star * \star}$ & $0.0167^{*}$ & $0.0374^{* *}$ \\
\hline Consumer Durables & $-0.514^{* * *}$ & $0.6970^{* * *}$ & $0.2522^{* * *}$ & 0.0516 & $-0.5154^{* * *}$ & $0.8697^{* * *}$ & $0.0539^{* * *}$ & 0.005603 \\
\hline Consumer Services & 0.1834 & $0.8581^{* * *}$ & $0.6020^{\star * *}$ & $0.059^{* *}$ & $-0.8710^{* * *}$ & $0.6872^{* * *}$ & $0.0910^{* *}$ & $0.10867^{* *}$ \\
\hline Diversified Financials & $-0.752^{* * *}$ & $0.8955^{* * *}$ & $0.5053^{* * *}$ & $0.0600^{*}$ & $-1.2247^{* * *}$ & $0.1985^{* *}$ & 0.000001 & $0.2952^{* * *}$ \\
\hline Energy & $-05776^{* * *}$ & $0.7804^{* * *}$ & $0.2434^{* * *}$ & $0.035^{\star \star}$ & $-0.9958^{* * *}$ & $0.7543^{* * *}$ & $0.343^{* * *}$ & 0.01451 \\
\hline Food Beverage & -0.185 & $0.8063^{* * *}$ & $0.2487^{\star * *}$ & $0.1117^{* *}$ & $-1.0423^{* * *}$ & $0.9085^{* * *}$ & $0.40202^{* * *}$ & 0.019485 \\
\hline Health care & $-0.698^{* * *}$ & $0.9533^{* * *}$ & $0.2170^{\star * *}$ & 0.0127 & $-0.8231^{* * *}$ & $0.9694^{* * *}$ & $0.21637^{\star \star \star}$ & 0.002213 \\
\hline Insurance & $-0.866^{* * *}$ & $0.478^{* * *}$ & $0.2333^{* * *}$ & $0.1244^{*}$ & $-0.9234^{* * *}$ & $0.9258^{* * *}$ & $0.0982^{* * *}$ & 0.002569 \\
\hline Materials & $0.04675^{\star * *}$ & $0.2757^{* * *}$ & $0.09^{* * *}$ & $0.5021^{* * *}$ & $-0.7043^{* * *}$ & $0.9225^{\star \star *}$ & $0.08098^{* * *}$ & 0.004706 \\
\hline Pharmaceuticals & $-0.749^{* * *}$ & $0.8883^{* * *}$ & 0.2216 & $0.0266^{*}$ & $-0.8846^{\star * *}$ & $0.9386^{* * *}$ & $0.17872^{* * *}$ & 0.014562 \\
\hline Real Estate & $-0.043^{* * *}$ & $0.8357^{* * *}$ & $0.5487^{* * *}$ & $0.0443^{*}$ & $-0.7006^{* * *}$ & $0.2385^{\star * \star}$ & 0.00000001 & $0.0882^{* * *}$ \\
\hline Transportation & $-0.518^{* * *}$ & $0.9790^{* * *}$ & $0.3557^{* * *}$ & $0.0026^{*}$ & $-0.8104^{* * *}$ & $0.9066^{* * *}$ & $0.11058^{* * *}$ & 0.00441 \\
\hline Technology & $0.3620^{* * *}$ & $0.8767^{* * *}$ & $0.3007^{* * *}$ & $0.0260^{* * *}$ & $-0.7109^{* * *}$ & $0.8318^{* \star *}$ & $0.12889^{* * *}$ & 0.00965 \\
\hline Utilities & $-0.551^{* * *}$ & $0.6713^{* * *}$ & $0.4210^{* * *}$ & 0.1011 & $-0.9117^{* * *}$ & 0.0511 & 0.000001 & $0.3349^{* * *}$ \\
\hline
\end{tabular}

Note: ${ }^{* *},{ }^{* *}$ and ${ }^{*}$ indicates significant at $1 \%, 5 \%$ and $10 \%$ level of significance based on t-statistics.

We have $\log \left[\operatorname{Std}_{\mathrm{c}}\left(\beta_{\mathrm{imt}}^{\mathrm{b}}\right)\right]=\mu_{\mathrm{m}}+H_{\mathrm{mt}}+\vartheta_{\mathrm{mt}}$ and $\mathrm{H}_{m t}=\varphi_{m} \mathrm{H}_{m t-1}+\mathrm{n}_{m t}$. If $\varphi_{m}$ and $\sigma_{\mathrm{m} \eta}^{2}$ that are significant, there is herding existence. 
of $\boldsymbol{h}_{m t}$ coefficient throughout observed periods by industries shows a more outstanding feature of state space model than CSAD index model because there is no need to limit regression running time and still observe the variation. The movement of herding level goes through different stages. According to Hwang and Salmon (2004), volatility of $\boldsymbol{h}_{\boldsymbol{m} t}$ indicates the level of herding. $\boldsymbol{h}_{m t}$ near 1 proves a strong evidence of herding. It can be seen in both Vietnam and Taiwan, industries such as Automobiles, Bank, Consumer Service, Diversified Financials, Energy, Food Beverage, Healthcare, Insurance, Pharmaceuticals, Technology, and Utilities always have graphs of $\boldsymbol{h}_{\boldsymbol{m} t}$ drawn above average levels. The blue graph shows the fluctuation of herding level. For assessing the impact of influenza pandemic panic using visual graphs, the author specially marked the stage of occurrence of H1N1 and COVID-19 pandemic for direct observation. The red line marks the timeline for H1N1 and COVID-19 appearance. At the time of the pandemic, different sectors had different responses, as shown by the uptrend reversal or the downtrend of the graph after the marked milestones. Through observation, we can see the reversal up or down of herding level when pandemics appear. In general, for industries where herding is strong and sensitive to the constant changing of abnormal events in the market, the graph often shows strong fluctuations and strong dispersion, others is more stable (See appendix)

It is easy to see that since the COVID-19 pandemic broke out, in Vietnam, defensive industries such as Capital Goods, Commercial, Energy, Food Beverage, Healthcare, Pharmaceuticals, Transportation, and Technology are particularly interested. Due to direct influences such as social isolation orders, the need to stock up on supplies and healthcare needs. But surprisingly, for the Taiwan market, the unpopular level of herding increased even decreased. This is completely consistent with the above analysis when herding phenomenon in Vietnam happens stronger than Taiwan.

From that, it can be concluded that the disease outbreak is an information that affects the investment behavior of market investors, but from a different perspective with each specific industry. Moreover, $\boldsymbol{h}_{m t}$ index thereby shows it's possible to develop more to the application as an indicator of the herding phenomenon.

\section{Conclusions and Discussions}

We find that the linear model based on the CASD testing methodology yields few significant evidence of herding. However, the State space models lead to consistent results demonstrating strong evidence of herd behavior in different industries. Noticeably, Christie and Huang's linear model (1995), excluding Insurance and Materials industries in Vietnam and Real Estate in Taiwan, offers no proof of investor herds. However, this approach, as previously stated, may lead to incorrect results.Just from the other aspect, the State space model suggests that herding will be beta calculated since the herding calculation relies on a relative distribution of the hypersensitivity for all market properties. The results of the return dispersion model are further supported by the usage of the national State space models proposed in Hwang and Salmon (2004), which demonstrate solid evidence for investor herd configuration in the various industries of Vietnam and Taiwan.

The author investigates herding in a sample in Vietnam as representing a frontier market and Taiwan, emerging market. Although Taiwan's equity market in comparison to the market in Vietnam is relatively developed and classified as an emerging market, its herding behavior was still high. This result was consistent with previous studies that have demonstrated herd behavior, including herding practices in Taiwan and other emerging markets, in different markets in Vo and Phan (2017) and Hsieh (2013). Both markets have herding that reduces the consistency of its insightful climate, thus allowing investors to find it a viable choice to obtain information from peers' trades. Moreover, the herding impact in the industries will be greater than with the aggregate market. This has been documented by finding significant evidence through State space models in both Vietnam and Taiwan.

The results indicated that up to 12 industries were found to have herding, while Taiwan had only five of 17 industries classified and observed. The reasonable explanation for this was that Vietnam is a frontier market, which tends to have low trade volumes leading to a small total proportion of inventory traded actively each day, thus placing a strong dependence on the decision to stock (in reality, trading at all) rather than on the output of each stock. Moreover, despite the relatively low transparency of market details, investors in bonds will consider herding as a feasible alternative, regardless of market direction. The frontier markets are a group for which, unlike emerging markets for which work is extensive, little awareness is made of their investors' propensity to herd. Moreover, among the emerging markets, Taiwan is one of the oldest markets with a more developed economy. Thereby, we can see the differences in the frontier and emerging markets when talking about herding, and partly see the limitations on the transparency and efficiency of the frontier market to emerging market.

The author also analyzes the impact of influenza panic on herds on different industries by limiting the observation time in the return dispersion model and analyzing the fluctuation of graphs of $h_{m t}$ coefficient in State space model throughout observed periods by industries. It shows that different industries respond differently to influenza pandemic panics through uptrend and downtrend demonstrations. Both models show the difference between the response of industries before and after the outbreak period. The results still show that in 
Taiwan market, an emerging and herding level market has changed due to the impact of changing conditions such as epidemics, but not as strongly as in Vietnam. From there, we see that the disease is a factor that not only creates anxiety for us from a health perspective,but causes psychological instability for investors when investing in the market.

\section{References}

Alam, M. N., Alam, M. S., \& Chavali, K. (2020). Stock Market Response during COVID-19 Lockdown Period in India: An Event Study. Journal of Asian Finance, Economics and Business, 7(7), 131-137. https://doi.org/10.13106/jafeb.2020. vol7.no7.131

Bikhchandani, S., \& Sharma, S. (2000). Herd behavior in financial markets. IMF Staff Papers, 47(3), 279-310.

Chang, E. C., Cheng, J. W., \& Khorana, A. (2000). An examination of herd behavior in equity markets: An international perspective. Journal of Banking \& Finance, 24(10), 1651-1679.

Chen, Y., Welling, M., \& Smola, A. (2012). Super-samples from kernel herding. Proceedings of the Twenty-Sixth Conference on Uncertainty in Artificial Intelligence (UAI2010). arXiv:1203.3472.

Chiang, T. C., \& Zheng, D. (2010). An empirical analysis of herd behavior in global stock markets. Journal of Banking \& Finance, 34(8), 1911-1921.

Christie, W. G., \& Huang, R. D. (1995). Following the pied piper: Do individual returns herd around the market? Financial Analysts Journal, 51(4), 31-37.

Economou, F., Kostakis, A., \& Philippas, N. (2011). Crosscountry effects in herding behavior: Evidence from four south European markets. Journal of International Financial Markets, Institutions and Money, 21(3), 443-460.

Henker, J., Henker, T., \& Mitsios, A. (2006). Do investors herd intraday in Australian equities? International Journal of Managerial Finance,2(3), 196-219. https://doi. org/10.1108/17439130610676475ss
Hsieh, S. F. (2013). Individual and institutional herding and the impact on stock returns: Evidence from Taiwan stock market. International Review of Financial Analysis, 29, 175-188.

Hwang, S., \& Salmon, M. (2004). Market stress and herding. Journal of Empirical Finance, 11(4), 585-616.

Jalal, R. N., Sargiacomo, M., Sahar, N. U., \& Fayyaz, U. (2020). Herding Behavior and Cryptocurrency: Market Asymmetries, Inter-Dependency and Intra-Dependency. Journal of Asian Finance, Economics and Business,7(7), 27-34. https://doi. org/10.13106/jafeb.2020.vol7.no7.027

Kallinterakis, V. (2007). Herding and the thin trading bias in a start-up market: Evidence from Vietnam. Available at SSRN 1105976. http://dx.doi.org/10.2139/ssrn.1105976

Khan, K., Zhao, H., Zhang, H., Yang, H., Shah, M. H., \& Jahanger, A. (2020). The Impact of COVID-19 Pandemic on Stock Markets: An Empirical Analysis of World Major Stock Indices. Journal of Asian Finance, Economics and Business, 7(7), 463-474. https://doi.org/10.13106/jafeb.2020.vol7.no7.463

Lin, A. Y., \& Swanson, P. E. (2003). The behavior and performance of foreign investors in emerging equity markets: Evidence from Taiwan. International Review of Finance, 4(3-4), 189-210.

Muth, J. F. (1961). Rational expectations and the theory of price movements. Econometrica, 29(3), 315-335. https://doi. org/0012-9682(196107)29:3<315:REATTO $>2.0 . C O ; 2-G$

Olsen, R. A. (1996). Implications of herding behavior for earnings estimation, risk assessment, and stock returns. Financial Analysts Journal, 52(4), 37-41.

Patterson, D. M., \& Sharma, V. (2007). Did herding cause the stock market bubble of 1998-2001?. Working Paper.The University of Michigan-Dearborn. https://pdfs.semanticscholar.org/ f04d/2d5ae95c23b1e4aafa4089c8dac159de2b26.pdf

Vo, X. V., \& Phan, D. B. A. (2017). Further evidence on the herd behavior in Vietnam stock market. Journal of Behavioral and Experimental Finance, 13, 33-41.

Wermers, R. (1999). Mutual fund herding and the impact on stock prices. The Journal of Finance, 54(2), 581-622. 


\section{Appendix}
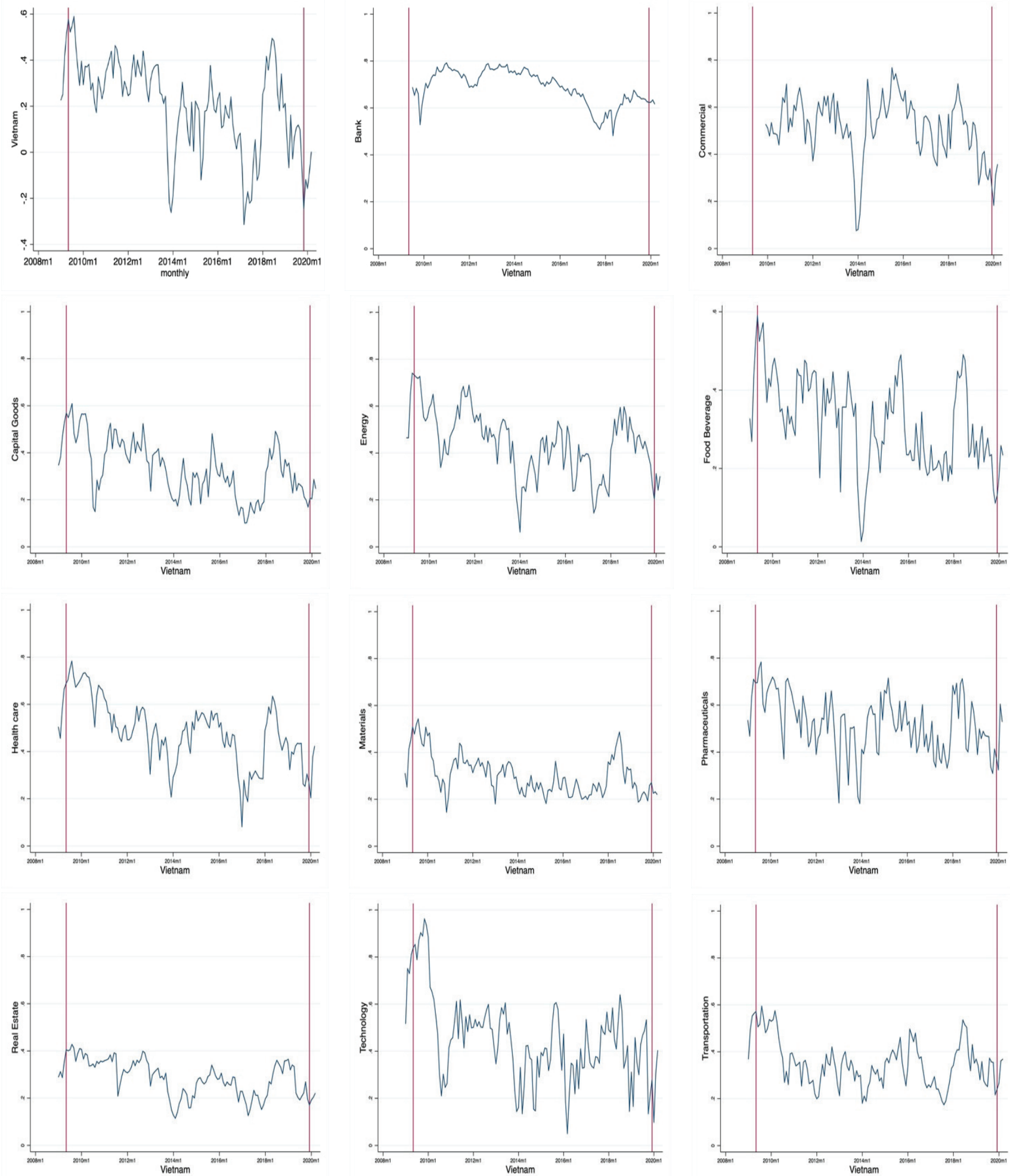

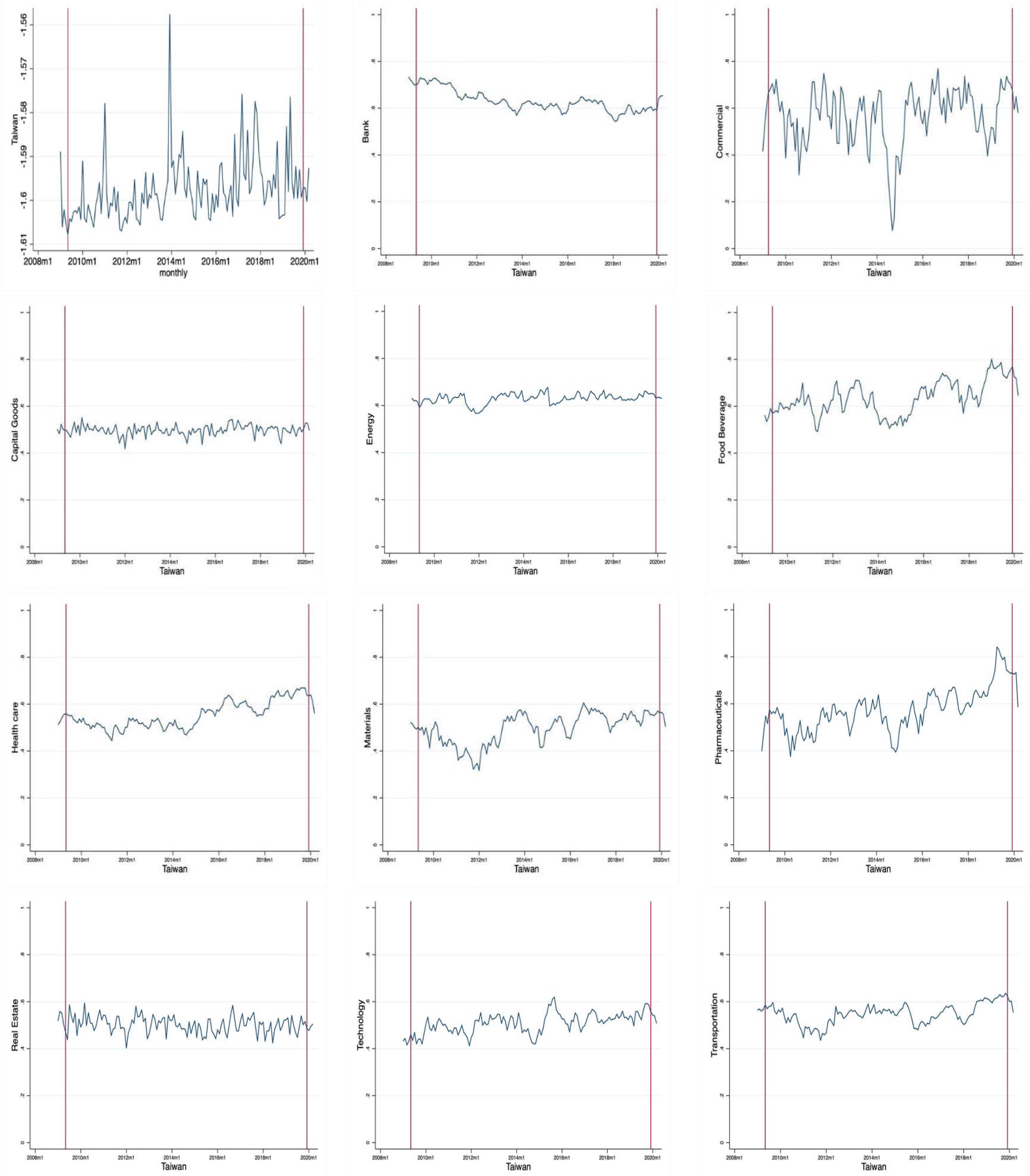

Figure: Graphs of $h_{m t}$ coefficient throughout observed periods of Vietnam and Taiwan stock market by industries. 